\title{
Dentición de titanosaurios (Dinosauria, Sauropoda) del Cretácico Superior de la provincia de Río Negro, Argentina: morfología, inserción y reemplazo
}

\author{
Rodolfo A. GARCÍA ${ }^{1,2}$ e Ignacio A. CERDA1,2
}

\begin{abstract}
Dentition of titanosaurs (Dinosauria, Sauropoda) from the Upper Cretaceous of Río Negro Province, ARgENTINA: MORPHOLOGY, IMPLANTATION AND REPLACEMENT. A fragment of dentary of a titanosaur sauropod from the Anacleto Formation (Upper Cretaceous of the Río Negro Province) is described. Inside the alveoli, functional and replacement teeth in successive "premature" stages are observed. At least in the preserved portion, an alternate teeth replacement pattern is observed. The histological analysis of this specimen allowed identifying the attachment dental tissues (alveolar bone, cementum and periodontal ligament). Numerous isolated teeth from the same unit and from the overlying Allen Formation are described. Based on these, a classification of the wear facets is proposed: 1) Teeth with only one facet: on the labial side, on the lingual side, or on the lateral side. 2) Teeth with two facets: the bigger on the labial side and the smaller on the lingual side; the bigger on the lingual side and the smaller on the labial side; the bigger on the lingual side and the smaller on the mesial or distal edge. 3) Teeth with three facets: one on the lingual side, the others on the mesial and distal edges; one on the lingual side, the others on the labial and mesial or distal edges; one on the labial side, the others on the mesial and distal edges. 4) Teeth with four facets: the smaller on the labial side, the bigger on the lingual side, and two lateral facets, one on the mesial and the other on the distal edges. Finally, we propose a hypothesis about the origin of the wear facets.
\end{abstract}

Resumen. Se describe un fragmento de dentario de saurópodo titanosaurio de la Formación Anacleto (Cretácico Superior de la provincia de Río Negro). Dentro de los alvéolos se hallan dientes funcionales así como dientes de reemplazo en sucesivos estadios de desarrollo. Al menos en la porción preservada del dentario, es posible advertir un patrón de reemplazo alternante de los dientes. El análisis histológico de este ejemplar, permite observar la naturaleza de los tejidos involucrados en la inserción dentaria (hueso alveolar, cemento y ligamento periodontal). De esta misma unidad y de la suprayacente Formación Allen, se describen numerosos dientes aislados. En base a estos dientes, se propone una clasificación para los diferentes tipos de facetas de desgaste: 1) Dientes con una única faceta: sobre el lado labial, sobre el lado lingual o lateral. 2) Con dos facetas: la mayor sobre el lado labial y la menor sobre el lado lingual; la mayor sobre el lado lingual y la menor sobre el labial; la mayor sobre el lado lingual y la menor sobre el mesial o distal. 3) Con tres facetas: una sobre el lado lingual, otra sobre el mesial y otra sobre el distal; una sobre el lado lingual, otra sobre el labial y otra sobre el mesial o distal; una faceta sobre el lado labial, otra sobre el mesial y otra sobre el distal. 4) Con cuatro facetas: una menor sobre el lado labial, otra mayor sobre el lingual y dos laterales, sobre los lados mesial y distal. Finalmente se propone una hipótesis de cómo se habrían originado mencionadas facetas de desgaste.

Key words. Dentition. Titanosaurs. Anacleto and Allen Formations. Replacement tooth.

Palabras clave. Dentición. Titanosaurios. Formaciones Anacleto y Allen. Reemplazo dentario.

\section{Introducción}

La particular dentición de los saurópodos es probablemente el reflejo de su especializada adaptación alimentaria (Coria y Chiappe, 2001; Upchurch et al.,

1INIBIOMA-Consejo Nacional de Investigaciones Científicas y Técnicas

2Museo de Geología y Paleontología Universidad Nacional del Comahue, Buenos Aires 1400, 8300 Neuquén, Argentina.

rgarcia@uncoma.edu.ar nachocerda6@yahoo.com.ar

CAsociación Paleontológica Argentina
2004; Sander y Clauss, 2008). Justamente, uno de los aspectos menos conocidos de los saurópodos y particularmente de los titanosaurios, es su mecanismo de alimentación y todo lo relacionado a su dentición; facetas de desgaste, reemplazo dentario, diversidad morfológica, entre otros aspectos (Upchurch y Barrett, 2000). Sin embargo, han sido numerosas las explicaciones acerca de las adaptaciones alimentarias y dietas de los saurópodos. Holland (1924) y posteriormente Haas (1963) propusieron una alimentación a base de bivalvos (malacofagia) en función de las facetas de desgaste en los dientes de Diplodocus Marsh, 1878. Osborn (1899), Hay (1908), Huene (1929) y AMGHB2-0002-7014/10\$00.00+.50 
Dodson (1990) entendieron a los saurópodos como consumidores de plantas acuáticas, o filtradores de plantas y animales planctónicos (Stevens y Parrish, 2005). Hummel et al. (2008) en un estudio reciente, en base al valor energético de numerosas plantas, proponen una dieta compuesta de helechos (e.g. Marattiaceae) y gimnospermas (e.g. araucarias y ginkgos). Ya sean consumidores de uno u otro grupo de plantas terrestres, son pocas las dudas acerca de la especificidad adaptativa a la herbivoría de estos animales. También se sabe que los saurópodos, así como otros vertebrados no mamíferos, presentan un continuo recambio dentario a lo largo de sus vidas (White, 1958; Erickson, 1997). Es así que los dientes de los saurópodos titanosaurios aparecen mayormente aislados y con una mayor abundancia que otras partes del esqueleto, debido en parte a la naturaleza de su composición como a su alta tasa de reemplazo. En escasos especimenes de titanosaurios (e.g. Antarctosaurus Huene, 1929; Laplatasaurus Huene, 1929 [Powell, 1979]; Muyelensaurus Calvo, González-Riga y Porfiri, 2007 [Calvo et al., 2007]; Titanosauria indet. MPCA 79 [Coria y Chiappe, 2001]) es posible observar no sólo los dientes funcionales sino la batería de dientes de reemplazo.

En cuanto al tipo de desgaste que presentan los dientes, numerosos autores (Fiorillo, 1991, 1997, 1998, 2008; Calvo, 1994; Wilson, 2005, Sereno et al., 2007) han explicado su origen en base principalmente a su micro-desgaste; sin embargo, hasta el momento no se ha propuesto ninguna explicación de cómo se habrían generado estas facetas.

Otro aspecto desconocido en relación a la dentición de los titanosaurios, radica en la naturaleza de los tejidos involucrados en la inserción dentaria. Los titanosaurios, al igual que el resto de los arcosaurios, poseen una típica inserción de tipo tecodonte. Según Gaengler (2000), el término tecodoncia se aplica sólo cuando el diente se encuentra alojado dentro de un alvéolo, e insertado mediante un complejo de tejidos que incluyen hueso alveolar, cemento y ligamento periodontal. De estos tejidos, el hueso alveolar es el que se interpone entre el diente y su pieza portadora (en este caso el dentario). Este tejido alveolar puede ser de tipo entretejido (woven fibered bone) o lamelar, dependiendo de su tasa de formación (Reid, 1996; Caldwell et al., 2003; Budney et al., 2006). El cemento es un tejido conectivo calcificado que cubre la raíz del diente y su función es la de brindar una superficie de anclaje para los ligamentos periodontales (Reid, 1996; Caldwell et al., 2003; Budney et al., 2006). En dinosaurios no avianos, las características micro-estructurales de los tejidos de inserción dentaria han sido poco estudiadas. Hasta el momento, sólo las descripciones histológicas efectuadas por Reid (1996) en algunos dinosaurios saurisquios y ornitisquios hacen referencia a este tipo de tejidos.

AMEGHINIANA 47 (1), 2010
En este trabajo se describe un fragmento de un dentario de titanosaurio que permite estudiar su composición dentaria, así como su patrón de reemplazo; asimismo, se describen los distintos tipos de tejidos involucrados en la inserción dentaria. Por otro lado, se analiza una colección única de aproximadamente 600 dientes provenientes de dos unidades geológicas contiguas (formaciones Anacleto y Allen, del Cretácico Superior de la provincia de Río Negro), presentándose por vez primera una completa clasificación de los tipos de facetas de desgaste. Con relación al desgaste de los dientes, se propone una hipótesis que explica el patrón observado.

\section{Materiales y métodos}

Los especimenes para este estudio provienen de dos unidades geológicas contiguas del Cretácico Superior, la Formación Anacleto (Campaniano medio-inferior) (Digregorio y Uliana, 1979; Dingus et al., 2000) y la suprayacente Formación Allen (Campaniano-Maastrichtiano) (Ballent, 1980). Ambas unidades estratigráficas afloran extensamente en la provincia de Río Negro, Argentina.

Se examinó un fragmento de dentario derecho procedente de la Formación Anacleto en cercanías de la ciudad de Cinco Saltos, Río Negro, Argentina. En primera instancia, se efectuaron tomografías axiales computadas (TAC) de la pieza mediante un tomógrafo Pro Speed helicoidal (serie 99783, Pro GP). Sin embargo, este análisis no proporcionó resultados positivos, posiblemente debido a la gran cantidad de elementos pesados, tanto en el sedimento que rellena los alvéolos como en los minerales que resultan del reemplazo diagenético. Sobre el hueso se realizó un molde y una copia, ambos depositados en la colección del Museo de Cinco Saltos (MCSPv-061). Posteriormente, se efectuaron sobre el material original cuatro cortes delgados longitudinales [MUCPh $251-5,6,7,8]$ y cuatro transversales [MUCPh 251-1, 2, $3,4]$, de los cuales sólo dos fueron descriptos.

Se han analizado unas 155 piezas dentales (MPCAPv- 6, 12, 15, 18, 19-21, 24, 25, 28, 30, 32, 37, 40, 43, 46, $48,51,52,54,55,64,68,72,75-77,84,87-89,90,92,96-$ $98,102,105,106,108,109,112,114-116,120-122,126-$ 129, 134-136, 138,139, 141, 143, 144, 147-152, 154, 155, 157, 159, 162-164, 167, 168, 170, 181, 184-188, 193, 196, 201-207, 209-211, 213, 214, 217, 220, 223, 224, 229, 245, 260, 272, 286, 288, 715-717, 719-721, 723-726, 730-733, 734-739, 740, 742-751, 752-757, 759, 760, 795, 798/1-8, 21299) seleccionadas de una colección de 559 especimenes procedentes de la Formación Anacleto, en inmediaciones del Lago Pellegrini y en Cinco Saltos, en la provincia de Río Negro. Estas piezas se encuentran depositadas en la colección del Museo "Carlos 
Ameghino" de Cipolletti, Río Negro, Argentina. Otros 27 dientes (MCSPv- 23, 51, 90-99, 101-104, 160, 162-170, 172,) fueron seleccionados de entre 31 especimenes que posee la colección del Museo de Cinco Saltos, todos procedentes de las cercanías de la ciudad homónima, y también de la Formación Anacleto. Se estudiaron tres dientes de la Formación Allen provenientes del Bajo de Santa Rosa, Río Negro (MML-221, 222, 223), los cuales se encuentran depositados en la colección del Museo de Lamarque. La gran mayoría de los dientes aislados aquí estudiados corresponden a piezas remplazadas en vida; así lo sugiere la pequeña y reabsorbida raíz, según la interpretación de Romer (1966) para reptiles en general.

Los materiales fueron observados y fotografiados a través de un microscopio óptico binocular (Olympus BX40), un microscopio estereoscópico binocular (Olympus SHZ10) y una cámara digital (Sony SSC$D C 50)$. Los micro-caracteres fueron observados con un microscopio electrónico de barrido (Phillips 515).

La terminología utilizada para la descripción de los dientes ha sido tomada de Nowinski (1971), Ten Cate (1995) y Upchurch y Barrett (2000) y es la siguiente: labial (la cara o lado externo), lingual (la cara interna), mesial (la cara rostral), distal (la cara caudal).

Abreviaciones institucionales. MCSPv, Museo Cinco Saltos, colección de paleovertebrados, Río Negro, Argentina; MML, Museo Municipal Lamarque, Río Negro, Argentina; MPCA-Pv, Museo Provincial "Carlos Ameghino", colección de paleovertebrados, Río Negro, Argentina; MUCPh, Museo Universidad Nacional del Comahue, colección de paleohistología, Neuquén, Argentina.

\section{Descripción del dentario}

El fragmento preservado corresponde a la porción media-rostral del dentario derecho de un titanosaurio (MCSPv-061) (único clado de saurópodos registrado en el Cretácico más superior), precisamente, la porción alveolar más caudal, que probablemente corresponda a los últimos siete alvéolos de la hilera (figura 1.1).

El alvéolo de posición más caudal observado corresponde al último de la hilera; así lo sugiere la presencia del foramen dental (figura 1.2). Caudalmente se extiende un segmento de $12 \mathrm{~mm}$ de longitud, en el cual no se encuentra ningún otro foramen dental que indique la existencia de otro alvéolo caudal a aquel último. El fragmento posee $4,3 \mathrm{~cm}$ de altura en su porción más alta y $7,9 \mathrm{~cm}$ de longitud (rostrocaudal) siendo su espesor medio (labio-lingual) de $1,9 \mathrm{~cm}$.

El borde ventral no se preservó, por lo que no es posible observar el canal Meckeliano. Este segmento del dentario posee una curvatura hacia la sínfisis; esta curvatura permite inferir que la mandíbula habría presentado una forma de " $\mathrm{U}$ " en su estado completo,
1

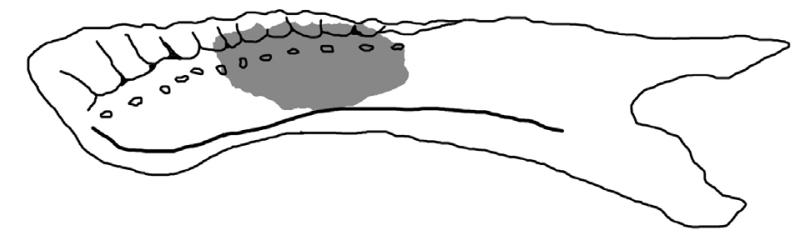

2

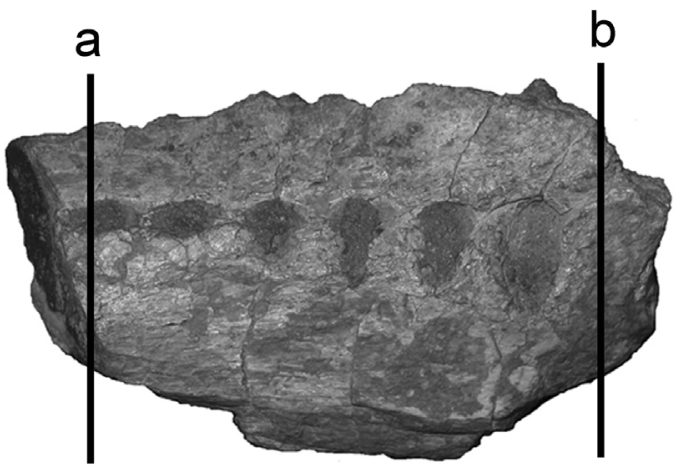

3

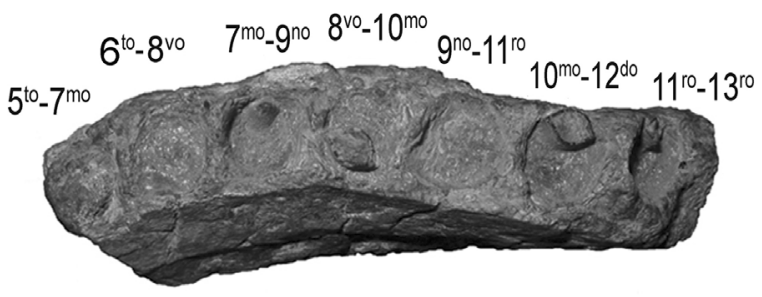

4

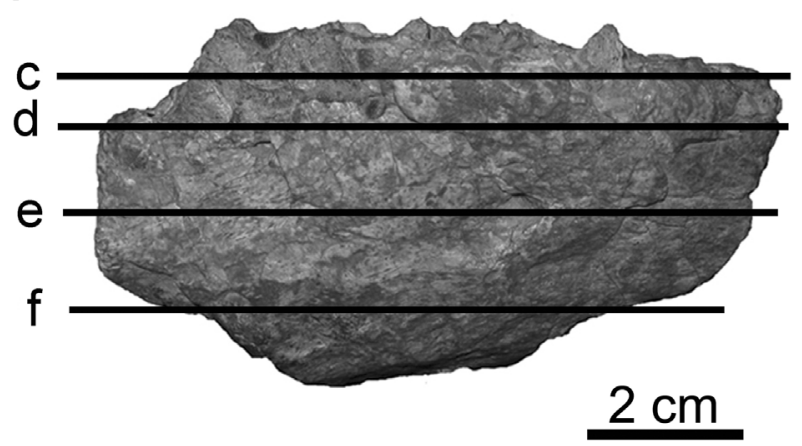

Figura 1. Titanosauria indet. (MCSPv- 061). Fragmento de dentario derecho. 1, reconstrucción aproximada del dentario en vista lingual. 2, fragmento de dentario en vista lingual. 3, el mismo en vista dorsal con la numeración estimada de cada alvéolo. 4, el mismo en vista labial. $\mathbf{a}-\mathbf{f}$, lugar donde se realizaron las secciones delgadas / Titanosauria indet. (MCSPv- 061). Fragment of right dentary. 1, dentary reconstruction. 2 , dentary in lingual view. 3, same in dorsal view with numeration of the alveoli. 4 , same in labial view. $\boldsymbol{a}-f$, thin- sections.

condición diferente a la presente en Antarctosaurus wichmannianus Huene, 1929 y Bonitasaura salgadoi Apesteguía, 2004, en donde las ramas del dentario 
son rostrocaudalmente rectas, curvándose hacia la sínfisis en su extremo rostral, casi en ángulo recto (Huene, 1929; Apesteguía, 2004). Los alvéolos más rostrales presentan una leve inclinación lateral (labial) con respecto al eje vertical.

Es probable que este espécimen (en base a la reconstrucción del dentario), al igual que otros titanosaurios (e.g. Bonitasaura salgadoi [Apesteguía, 2004]; Antarctosaurus wichmannianus [Huene, 1929], Nemegtosaurus mongoliensis Nowinski, 1971, [Wilson, 2005], Karongasaurus gittelmani Gomani, 2005, [Gomani, 2005], Rapetosaurus krausei Curry Rogers y Forster, 2001, [Curry Rogers y Forster, 2004]), haya llevado entre 11 y 13 alvéolos por dentario.

Entre el primer y séptimo alvéolo de la porción preservada (entre los probables alvéolos quinto o séptimo y 11ro o 13ro del dentario completo), los mismos no exponen significativas diferencias de tamaño, siendo su contorno circular, de un diámetro de $8 \mathrm{~mm}$ aproximadamente (figura 1.3), y correspondiendo perfectamente cada uno de ellos con su foramen dental de posición lingual (figura 1.2).

La perdida de la pared rostral del primer alvéolo de la hilera (probablemente el quinto o séptimo), permite observar que éste se encuentra relleno de algún mineral ferroso, aparentemente sin restos de dientes.

El segundo alvéolo de la hilera (probablemente el sexto u octavo) no presenta ningún diente a simple vista (figura 1.3). Sin embargo, en el primer corte transversal (figura 1.2a) se observan dos dientes emergiendo desde lo profundo del alvéolo, el ápice del primero se encuentra a menos de $10 \mathrm{~mm}$ del borde superficial del alvéolo, sobre la pared lingual (figura 2.5). El segundo de los dientes es más profundo, y se encuentra inmediatamente por debajo del primero, en contacto con la pared labial. El diente funcional de este alvéolo probablemente se haya perdido post-mortem o en momentos de soterramiento. Caudalmente al alvéolo recién descrito, sobre el tercer alvéolo de la hilera (probablemente el séptimo o noveno), se muestra sobre la pared labial el ápice de un diente, interpretado como una pieza de reempla-

Figura 2. Sucesivas secciones delgadas del dentario de Titanosauria indet. 1-4, secciones longitudinales (MUCPh 251-5, MUCPh 251-6, MUCPh 251-7, MUCPh 251-8), indicadas en figura 1.4 c-f, respectivamente. 5 y $\mathbf{6}$, secciones transversales (MUCPh 251-4, MUCPh 251-3) indicadas en figura 1.2a, b, respectivamente. La numeración correspondería a la serie alveolar de un dentario completo. La flecha blanca en 1 indica un diente anómalo / successive thin sections of the Titanosauria indet. dentary 1-2, longitudinal sections (MUCPh 251-5, MUCPh 251-6, MUCPh 251-7, MUCPh 251-8) indicated in figure $1.4 c-f$ respectively. 5 y 6 , transversal sections (MUCPh 251-4, MUCPh 251-3) indicated in figure 1.2a, $b$ respectively. The numeration would correspond to the alveolar series of the complete dentary. White arrow in 1 is pointing to the anomalous tooth.

AMEGHINIANA 47 (1), 2010
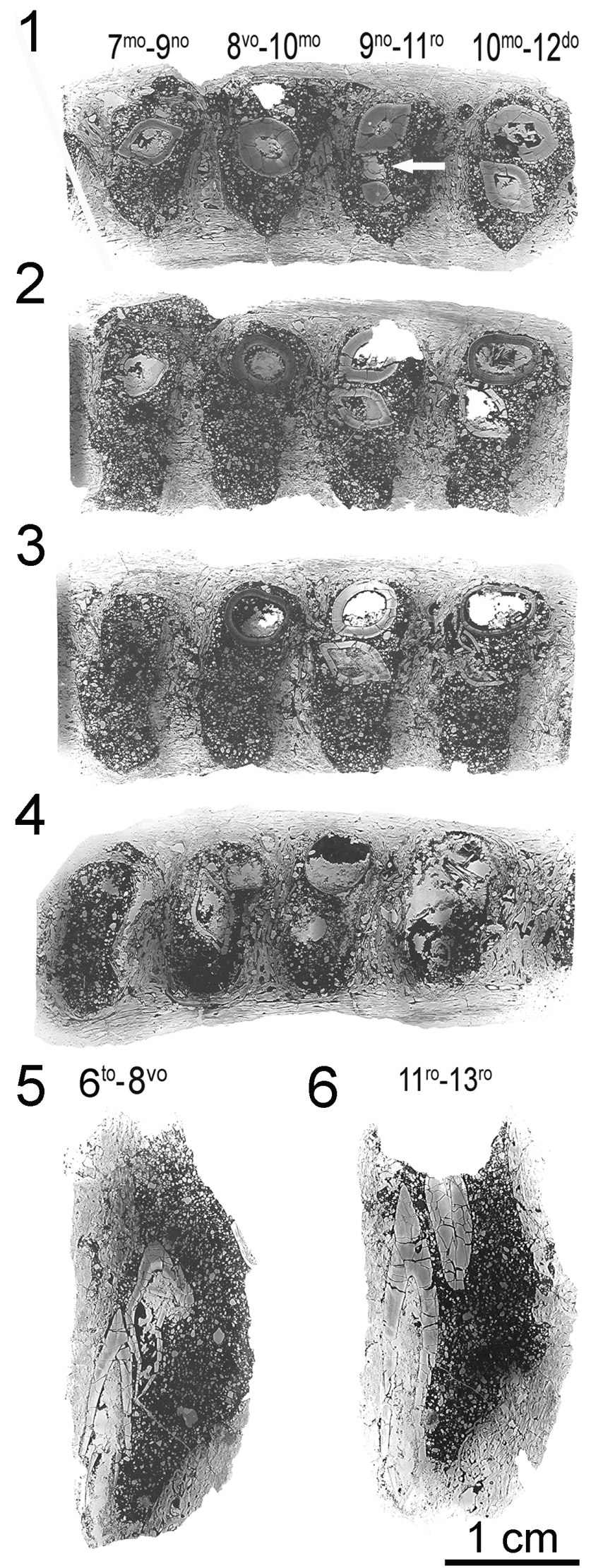
zo, ya que se encuentra inmediatamente por debajo del borde superior del alvéolo y sin ningún tipo de desgaste (figura 1.3). Este diente se encontraba pronto a ser funcional; probablemente habría ya desplazado al diente activo hasta ese momento, por lo que este alvéolo se encontraba momentáneamente sin su diente funcional. En este mismo alvéolo, en los sucesivos cortes longitudinales (figura 1.4c-f), no se aprecia en profundidad ningún otro diente de reemplazo (figura 2.2-4).

El cuarto alvéolo de la hilera (probablemente el octavo o décimo) presenta sobre el margen lingual un diente fracturado transversalmente a nivel del margen superior del alvéolo (figura 1.3); ésta es la pieza funcional del alvéolo. Profundo en el alvéolo, este mismo diente se ubica algo labial. Sobre un corte longitudinal profundo (figura 2.3), se observa en el diente funcional el segmento radical, con una cavidad pulpar muy desarrollada. En un corte longitudinal aún más profundo (figura 2.4), en el centro del alvéolo, se observa la porción medio-apical de un diente de reemplazo y, labial a éste y en un muy mal estado de preservación, un tercer diente pequeño (un segundo diente de reemplazo).

En el quinto alvéolo de la hilera (probablemente el noveno o 11ro), no se observa ningún diente superficialmente (figura 1.3), sin embargo, en el primer corte longitudinal (figura 2.1) se observan dentro del alvéolo tres dientes a diferentes profundidades. El diente más maduro, o más pronto a erupcionar, se ubica sobre la pared labial del alvéolo, mientras que lingualmente a éste se encuentran los dos dientes restantes de menor tamaño. Estos dos últimos dientes, a pesar de tener tamaños similares en sección, difieren en la proporción entre el esmalte-dentina y cavidad pulpar. El de posición más labial (el del medio con respecto a los tres dientes) (indicado con una flecha en la figura 2.1 y pintado de negro en la figura 3), posee una cavidad pulpar muy desarrollada con respecto tanto a la capa de esmalte-dentina como a la cavidad pulpar del diente de posición más lingual. Este diente de proporciones anómalas, recuerda a la sección sobre la porción media de la corona de un diente funcional, o al menos de un diente más desarrollado. En tanto el tercer diente, presente sobre la pared lingual del alvéolo (por su posición, en un estadio menos desarrollado) expone una sección (a nivel de la corona) levemente mayor a la presente en el diente anómalo. En un corte más profundo (figura 2.2), no se observa en este mismo alvéolo el diente considerado anómalo que se dispone entre los otros dos en el corte anterior (figura 2.1). En tanto, en este mismo corte y en los sucesivos, los dientes de posición labial y lingual aumentan su diámetro (figura 2.3, 4). La cavidad pulpar también incrementa su diámetro hacia la raíz del diente, mientras que su contorno elíptico (en la corona) cambia gradualmente a circular. Por un lado, este alvéolo estaría indicando la ausencia de un diente funcional en el momento de la muerte del animal; por el otro, el diente que se encuentra entre los otros dos (el más pequeño) recuerda (por la proporción esmalte-dentina/-cavidad pulpar) la sección de un diente de estadio más avanzado de desarrollo, pero de menor tamaño. Esto sugiere una anomalía en la mencionada pieza dentaria, probablemente un germen dentario que detuvo su desarrollo, en definitiva, un diente que nunca llegaría a ser funcional.

Sobre la abertura del sexto alvéolo de la hilera (probablemente el décimo o 12do), se observa un diente funcional fracturado a nivel del límite superior de la pared alveolar (figura 1.3). Este diente de contorno elíptico se encuentra en contacto con la pared labial del alvéolo; lingualmente a éste emerge el ápice fracturado de un diente de reemplazo. En los sucesivos cortes (figura 2 .1-3) la morfología de los dientes es similar a la de los demás (en sección apical con pronunciadas carenas, cambiando su contorno a elíptico-subcircular hacia la raíz). En el corte más profundo del alvéolo (figura 2.4), es posible identificar el extremo apical de un segundo diente de reemplazo, ubicado sobre la pared lingual.

El último alvéolo de la hilera, el séptimo (probablemente el 11ro o 13ro), y tal vez el último del dentario, se encuentra parcialmente preservado. Parte de la pared caudolateral no se preservó, por lo tanto, el alvéolo expone gran parte de su cavidad interna. Sobre la pared labial se apoya un diente fracturado que posiblemente (en base a su posición profunda en el alvéolo) sea un diente de reemplazo pronto a erupcionar (figura 1.3). Junto a éste, sobre su lado lingual, se observa el ápice fracturado de un segundo diente de re-

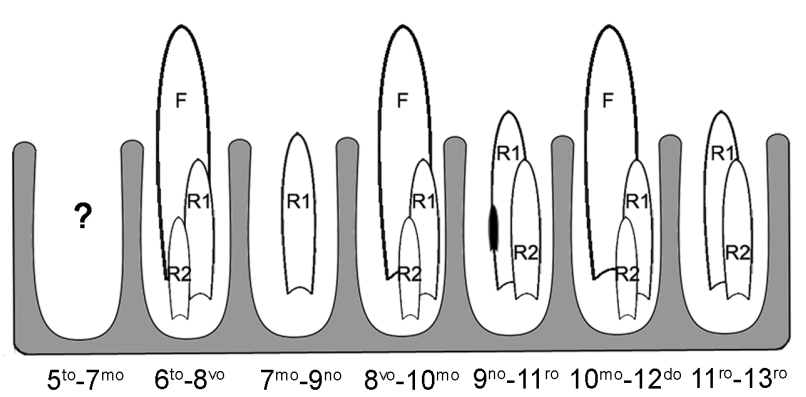

Figura 3. Esquema interpretativo del reemplazo de dientes en el dentario fragmentario de un Titanosauria indet. (MCSPv-061) en vista lingual. La numeración en la base del dibujo indica la posición de los alvéolos. F, diente funcional; R1, primer diente de reemplazo; R2, segundo diente de reemplazo; el diente pequeño en color negro representa un diente anómalo / interpretative drawing of the replacement tooth in a fragmentary dentary of Titanosauria indet. (MCSPv-061) in lingual view. The numeration at the bottom of the figure shows the alveoli positions. $\boldsymbol{F}$, functional tooth; R1, first replacement tooth; R2, second replacement tooth; the black small tooth represents an anomalous tooth. 
emplazo. El diente funcional, en base al amplio espacio vacío que se observa en el interior del alvéolo, se habría perdido en una etapa previa al soterramiento. En el corte transversal de este alvéolo (figura 1.2b) es posible observar a los dos diente de reemplazo recién descriptos en posición, dentro del alvéolo (figura 2.6).

\section{Morfología de los dientes del dentario}

Todos los dientes (tanto funcionales como de reemplazo) presentes en el dentario poseen la misma morfología. En una sección apical el contorno es elíptico, la cavidad pulpar diminuta, y la capa de dentina proporcionalmente importante; en una sección media (en la corona), la cavidad pulpar se hace notablemente más amplia y los bordes laterales del diente (mesial y distal) presentan agudas carenas. Hacia la raíz del diente la cavidad pulpar se amplía, las carenas pierden agudeza hasta que su contorno se hace aproximadamente circular y la proporción de dentina disminuye con relación a las secciones más apicales.

La superficie del esmalte sólo pudo ser observada en el diente de reemplazo del tercer alvéolo (séptimo o noveno de la hilera), y en menor medida en el diente funcional del alvéolo seis (décimo o 11ro). Éste presenta un aspecto levemente rugoso. La pobre preservación de la porción superior de los dientes funcionales no permitió observar el patrón de las facetas de desgaste.

\section{Reemplazo de dientes en el dentario}

Los saurópodos poseían un reemplazo dentario continuo durante sus vidas (Huene, 1929; Nowinski, 1971; Powell, 1979; Coria y Chiappe, 2001). Como sugieren Coria y Chiappe (2001), el reemplazo dentario de los saurópodos difiere notablemente del de otros saurisquios. En los primeros, el reemplazo dentario se produce, dentro de cada alvéolo, con un sentido lingual-labial, desde los dientes más inmaduros a los funcionales, siendo el diente reemplazado el de posición más labial. Los gérmenes dentarios se generan profundamente en el alvéolo, y a medida que estos se desarrollan se desplazan (linguo-labialmente) hacia la abertura del alvéolo, donde finalmente erupcionan y pasan a ser dientes funcionales (Romer, 1966), como observaron Coria y Chiappe (2001) en un premaxilar de titanosaurio indeterminado (MPCA-79).

La escasa porción preservada del dentario analizado (siete alvéolos, seis de ellos con dientes implantados), limita el conocimiento acerca de cómo habría sido el patrón de recambio dental en el dentario completo. A pesar de esto, al menos en la porción estuAMEGHINIANA 47 (1), 2010 diada, el reemplazo de dientes es alternado (figura 3), un patrón registrado en algunos vertebrados no mamíferos (Edmund, 1960; Osborn, 1977). Como se describió anteriormente, el primer alvéolo (quinto o séptimo) no permite observar dientes en su interior. El segundo alvéolo (sexto u octavo), a su vez, tiene el diente funcional y dos piezas de reemplazo. El siguiente alvéolo (séptimo o noveno), sólo presenta un diente de reemplazo muy pronto a ser funcional. El alvéolo octavo o décimo lleva su diente funcional y dos dientes de reemplazo. Caudal a éste, el alvéolo noveno o 11ro, no presenta diente funcional y sí un diente pronto a ser funcional, más otro diente de reemplazo. El décimo o 12do alvéolo, posee su diente funcional y dos dientes de reemplazo, mientras que el último alvéolo de la serie carece de diente funcional; éste sólo conserva dos dientes de reemplazo, uno de ellos pronto a erupcionar. Por lo tanto, el recambio de dientes, al menos en el dentario, habría sido de tipo "ola de reemplazo alternante" (figura 3) condición similar a la descrita por Nowinski (1971) y Wilson (2005) en la mandíbula inferior de Nemegtosaurus Nowinski, 1971.

En todos los alvéolos preservados, el diente funcional se ubica en la cara labial del alvéolo, mientras que los dientes de reemplazo erupcionan progresivamente desde la base del alvéolo, siempre desde su lado lingual, desplazándose linguolabialmente hasta ocupar la posición definitiva, lo que también se observa en los titanosaurios MPCA-79 (Coria y Chiappe, 2001), Antarctosaurus (Huene, 1929) y Muyelensaurus (obs. pers.).

\section{Histología}

Pese a la alteración diagenética que ha sufrido la muestra, es posible efectuar una caracterización general de su micro-estructura ósea. Tanto en las secciones transversales como en las longitudinales es posible observar a los alvéolos ocupar una importante proporción de la muestra, alcanzando profundamente la región basal del dentario. El tejido óseo es de origen secundario y se encuentra restringido a los márgenes labial y lingual, así como a los tabiques interalveolares. Las paredes labial y lingual del dentario se componen de tejido haversiano denso (figura $4.1,2)$. Dado que el tejido cortical más externo ha desaparecido en su totalidad, no es posible reconocer tejido sub-periosteal. El tejido haversiano está conformado por abundantes osteones secundarios de distintas generaciones, delimitados entre sí por conspicuas líneas de cemento. Cada osteón encierra de uno a tres canales vasculares con orientación variable, salvo en la región labial, donde tienden a dirigirse en sentido longitudinal. Los tabiques interalveola- 

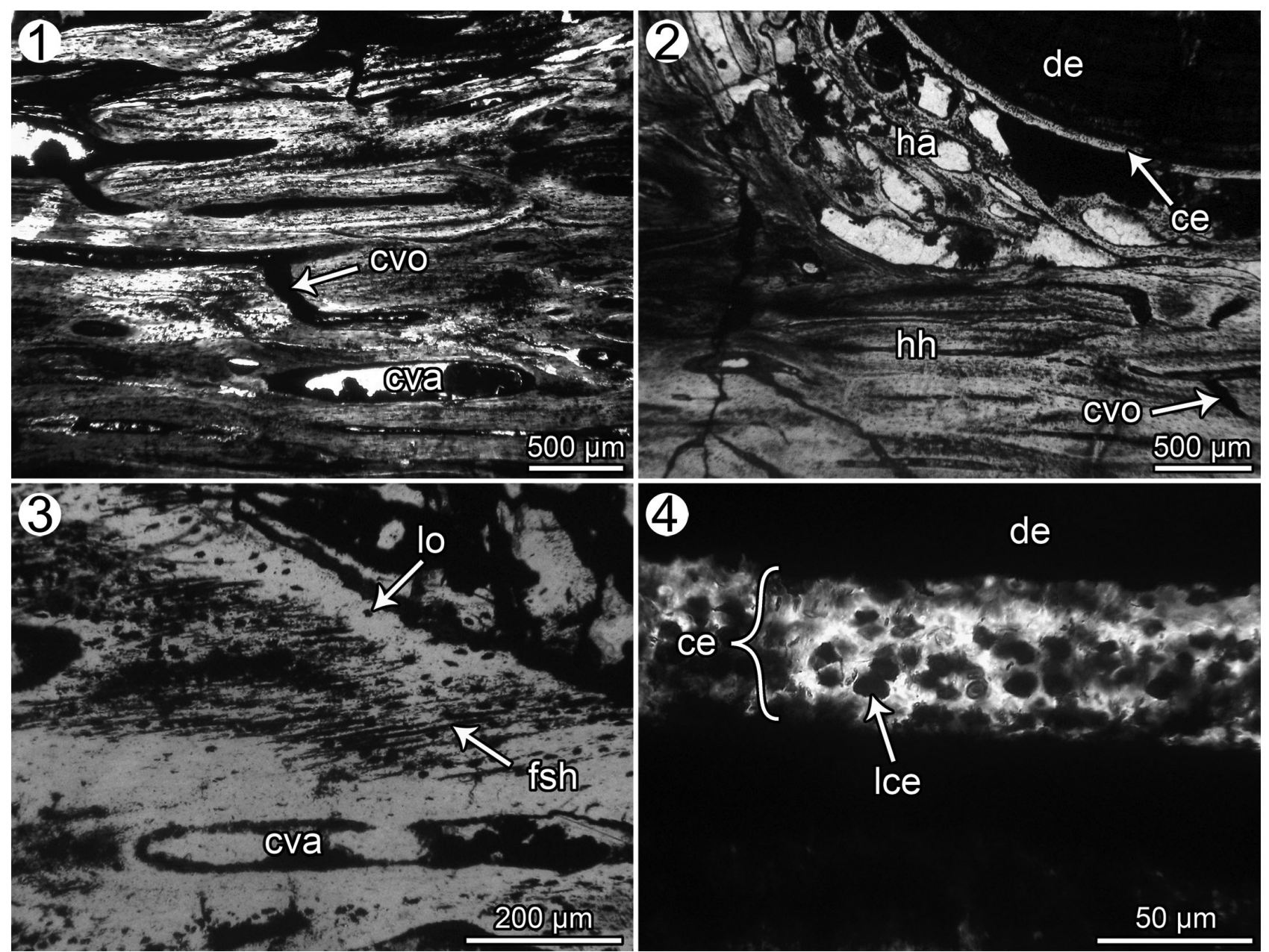

Figura 4. Titanosauria indet. Micro-estructura ósea del dentario. 1, sección longitudinal del dentario exhibiendo tejido haversiano (MUCPh 251-5), 40x. 2, sección longitudinal mostrando tejido haversiano del dentario, hueso alveolar, cemento y diente (MUCPh 2516), 40x. 3, fibras de Sharpey embebidas en el hueso alveolar (MUCPh 251-3), 100x. 4, capa de cemento celular recubriendo la raíz del diente (MUCPh 251-7), 100x. ce, cemento; cva, canal vascular; cvo, canal de Volkman; de, dentina; fsh, fibras de Sharpey; ha, hueso alveolar; hh, hueso haversiano; lce, laguna de cementocito; lo, laguna de osteocito / Titanosauria indet. Bone microstructure of the dentary. 1, longitudinal section of the dentary showing haversian tissue (MUCPh 251-5), 40x . 2, longitudinal section of the dentary showing haversian bone, alveolar bone, cementum and tooth (MUCPh 251-6), 40x. 3, Sharpey fibers imbibed in the alveolar bone (MUCPh 251-3), 100x. 4, cellular cementum layer coating the root tooth (MUCPh 251-7), 100x. ce, cementum; cva, vascular canal; cvo, Volkman's canal; de, dentine; fsh, Sharpey fibers; ha, alveolar bone; $\boldsymbol{h}$, Haversian bone; lce, cementum lacuna; lo, osteocyte lacuna.

res exhiben importantes vacuidades revestidas internamente por tejido lamelar. Dichos espacios otorgan un aspecto finamente esponjoso a los tabiques. Un rasgo particular de la muestra es la presencia de "estrías" en el tejido lamelar, distribuidas en pequeñas agrupaciones y proyectadas radialmente a partir de cada espacio interno. Estas marcas sólo pueden ser observadas en determinados sectores.

La superficie interna de los alvéolos está revestida por hueso alveolar, el cual se encuentra profundamente alterado (figura 4.2). Una de las secciones estudiadas (MUCPh 151-3) permite observar al menos dos generaciones de hueso alveolar, separadas por una tenue línea de cemento. Histológicamente, el hueso alveolar se diferencia del haversiano por la forma y distribución de sus lagunas de osteocitos, las cuales presentan un aspecto globoso y se distribuyen de forma desorganizada. Asimismo, la relativa amplitud de los espacios internos del hueso alveolar le confiere un aspecto finamente esponjoso. Si bien gran parte del hueso alveolar ha sido removido, encontrándose fragmentos aislados en las cavidades alveolares, en ciertos sectores se observa el contacto directo entre la base del hueso alveolar y el tejido haversiano, delimitado por una línea de reversión. Pese al grado de alteración sufrido por la muestra, es evidente que el espesor de la capa de hueso alveolar varía en distintas porciones del alvéolo. Las secciones transversales (MUCPh 251-3, 251-4), revelan la presencia de fibras de Sharpey embebidas en la matriz (figura 4.3). Estas fibras se orientan en sentido casi paralelo a la superficie interna del alvéolo.

Además del hueso alveolar, es posible identificar 
en la muestra otro tipo de tejido de inserción dentaria. En la porción correspondiente a la raíz de los dientes ubicados adyacentes a la pared labial en los alvéolos octavo-décimo, noveno-11ro y décimo-12do (figura 2.2-4), y adyacentes a la pared lingual en los alvéolos sexto-octavo y 11ro-13ro (figura 2.5, 6), la dentina se encuentra recubierta por una delgada capa de cemento celular. El mismo se caracteriza por ser avascular y presentar numerosas lagunas de cementocitos de aspecto globoso (figura 4.2,4). Las lagunas se encuentran embebidas en una matriz isótropa. Si bien no se registró cemento acelular, algunos sectores exhiben una banda de tejido muy denso, ubicado por debajo del cemento celular. Dada la alteración que presenta la muestra, no es posible discernir si se trata de cemento acelular o bien una porción alterada de dentina. La matriz del cemento carece de restos fibrosos.

\section{Diversidad morfológica en dientes de titanosaurio}

La morfología de los dientes en "forma de lápiz" es compartida por dos clados de neosaurópodos: los titanosaurios (excepto Malawisaurus) y los diplodocoideos, aunque ambos grupos difieren en la morfología y disposición de sus facetas de desgaste (Calvo, 1994). Los dientes de titanosaurio (excepto Malawisaurus) son cilíndricos, delgados, mayormente subcirculares en sección transversal y carecen totalmente de dentículos en sus coronas (Nowinski, 1971; Kues et al., 1980; Calvo, 1994; Kellner, 1996; Wilson y Sereno, 1998). El lado labial es con frecuencia levemente convexo, mientras que su lado lingual posee una tenue concavidad, aunque en numerosos ejemplares de titanosaurios, incluido algunos de los elementos estudiados aquí, este lado del diente es mayormente recto. A pesar de la aparente homogeneidad morfológica, los dientes de los titanosaurios procedentes de las formaciones Anacleto y Allen de la provincia de Río Negro estudiados en este trabajo presentan una notable diversidad, tanto en tamaño (longitud y diámetro) como en color, facetas de desgaste, superficie del esmalte y morfología de perímetro (sección transversal).

\section{Morfología general}

Todos los dientes sin excepción son prácticamente cilíndricos, delgados y levemente curvados. A partir de dientes alojados en sus respectivos alvéolos, en premaxilares, maxilares y dentarios de numerosos neosaurópodos, es posible confirmar que el plano lingual es (en el sentido axial) levemente cóncavo, mientras que el plano labial es convexo; sin embargo, este último plano es notablemente más curvado que AMEGHINIANA 47 (1), 2010 el plano lingual (Upchurch, 1995, 1998; Kellner, 1996; Barrett et al., 2002; Upchurch et al., 2004; Sereno y Wilson, 2005). Otros especimenes como Alamosaurus Gilmore, 1922 (Kues et al., 1980) y numerosos ejemplares aquí estudiados poseen su plano lingual recto. A diferencia de los saurópodos basales que presentan la corona de los dientes mesiodistalmente expandida y labiolingualmente comprimida (Madsen et al., 1995; Upchurch et al., 2004; Chatterjee y Zheng, 2005), los dientes de titanosaurios estudiados poseen sus márgenes prácticamente paralelos. Sus planos labial y lingual se contactan en los laterales (mesial y distalmente), formando en numerosos casos un borde agudo, una carena o arista, como en Antarctosaurus (Huene, 1929), Rinconsaurus Calvo y González-Riga, 2003 (Calvo y González-Riga, 2003), Alamosaurus (Kues et al., 1980), el ejemplar MPCA-79 (Coria y Chiappe, 2001), Bonitasaura Apesteguía, 2004 (Apesteguía, 2004) y en los dientes del dentario descrito anteriormente (MCSPv-061). Estos bordes agudos recorren todo el largo del diente, atenuándose hacia la raíz hasta ser imperceptibles. Estas dos aristas pueden estar centradas en el diente (sobre su eje mesio-distal) o desplazadas de este eje hacia el plano lingual, como sucede en Rinconsaurus (Calvo y Gonzalez-Riga, 2003) y Pitekunsaurus Filippi y Garrido, 2008 (Filippi y Garrido, 2008). Todos los especimenes observados, al igual que los dientes de todos los titanosaurios, carecen de dentículos. Los dientes que poseen sus aristas centradas exponen en sección transversal una simetría elíptica, mientras que los dientes con las aristas no centradas, poseen una sección en forma de " $\mathrm{D}$ ".

El desgaste dentario, siempre presente en dientes funcionales, puede presentarse con distintos patrones; con una única y simple superficie de rozamiento, sobre su cara lingual o labial o con un par de superficies de desgaste, una en la cara labial y otra en la lingual; en este patrón, esta última es por lo general la más desarrollada. Adicionalmente a los dos patrones recién mencionados, pueden ser observados dientes con facetas múltiples y complejas, como se discutirá más adelante. En su mayoría, los ejemplares aquí descriptos poseen sus raíces notablemente pequeñas y reabsorbidas, lo que, según Romer (1966), Kues et al., (1980) y Kellner (1996), indica que fueron remplazados en vida.

\section{Sección en corte transversal}

En corte transversal, los dientes varían su morfología dependiendo de la sección. Básicamente, es posible identificar tres morfologías a lo largo del diente. 1) Sobre la porción distal de la corona, cerca del ápice, siempre en dientes no funcionales o que comenzaban a ser funcionales, la sección es circular-subcir- 
cular. 2) En una posición media de la corona los dientes presentan una forma que puede variar (seguramente dependiendo del taxón) entre una forma elíptica y una forma de " $\mathrm{D}$ "; esta diferencia dependerá de la ubicación de las aristas a lo largo del diente. En los ejemplares donde las aristas corren centradas a lo largo del diente, la sección mostrará un contorno elíptico, mientras que en los ejemplares donde las aristas que recorren el diente están desplazadas del centro, su sección será en forma de " $\mathrm{D}$ ". En ambas morfologías, los bordes laterales (mesial y distal) terminan en ángulos agudos formando las aristas anteriormente mencionadas. 3) En la porción basal de la corona, o en el límite de ésta con la raíz, la sección es prácticamente circular.

\section{Tamaño}

La característica más variable que presentan los dientes es el tamaño. Su longitud, diámetro, y la combinación de ambas medidas, generan un espectro enorme de tamaños, por ejemplo: el diámetro (medido en la parte media de la corona, mesio-distalmente) tiene un rango desde $1,5 \mathrm{~mm}$ en el ejemplar MPCA$\mathrm{Pv}$ - 181, hasta $11 \mathrm{~mm}$ en el ejemplar MPCA-Pv- 170, mientras que la longitud (tomada desde el ápice a la raíz) va desde $11 \mathrm{~mm}$ en el ejemplar MPCA-Pv- 21, a $43 \mathrm{~mm}$ en el ejemplar MCAPv- 93. Sin embargo, algunos dientes fragmentarios indican tamaños aún mayores. La diversidad de tamaños (largos, anchos, dientes esbeltos o robustos) estaría en función del tamaño del individuo, así como de la edad del mismo. A pesar de esto, es probable que la diversidad morfológica observada en esta colección de dientes, esté correspondida también con una diversidad taxonómica.

\section{Facetas de desgaste}

Aparentemente, todos los dientes funcionales presentan faceta de desgaste. Estos planos son el resultado de la constante fricción generada por el rozamiento entre los dientes del premaxilar o maxilar (superiores) y los dientes del dentario (inferiores), en el ejercicio permanente de apertura y cierre de la boca para obtener el alimento. La ausencia de un aparato masticatorio, como señala Coombs (1975), habría estado vinculada, presumiblemente, a la innecesariedad de moler el material vegetal en la boca, ya sea por la presencia de una molleja en el estomago o de algún mecanismo químico o bacteriano en el intestino. A pesar de la ausencia de un aparato masticador, los neosaurópodos poseen un diverso patrón en las facetas de desgaste. Sereno y Wilson (2005) y Sereno et al., (2007) explicaron el origen de algunas de las facetas (labial y lingual) en los dientes de Nigersaurus Sereno, Beck, Dutheil, Larsson, Lyon, Moussa, Sadlier, Sidor, Varricchio, Wilson, Wilson, 1999 (un rebaquisáurido) de la siguiente manera: la faceta lingual (la más desarrollada de las dos y de bajo ángulo con respecto al eje axial del diente) se habría generado por abrasión diente contra diente, mientras que la faceta labial (menos desarrollada y de mayor ángulo) habría estado originada por el contacto con material vegetal. Nosotros observamos, a partir de la numerosa colección de dientes de titanosaurios estudiada, una diversidad de facetas de desgaste mucho mayor a la observada en el rebaquisáurido africano y en otros saurópodos. A partir de aquellas observaciones, consideramos poco probable el origen de la faceta labial de la manera que proponen Sereno et al., (2007). Como recién se mencionó, la morfología, tamaño, ubicación e inclinación de las facetas de desgaste es muy variable en los dientes de titanosaurios y es muy poco lo que se ha dicho acerca de su origen. Aún más escasas han sido las explicaciones dadas para los dientes que poseen dos facetas de desgaste (labial y lingual) o más, y siempre teniendo en cuenta que su movimiento "masticatorio" (los saurópodos no poseían un sistema masticatorio, Coombs, 1975; Sander y Clauss, 2008) habría sido aparentemente ortal (Calvo, 1994; Chatterjee y Zheng, 2002; Sereno et al., 2007).

En base a su cantidad y posición en el diente, las diferentes facetas de desgaste, pueden clasificarse de la siguiente manera:

1) Dientes con una única faceta: sobre el lado lingual; sobre un lateral (mesial o distal) o sobre el lado labial.

2) Con dos facetas: la mayor sobre el lado labial y la menor sobre el lingual; la mayor sobre el lado lingual y la menor sobre el labial; una sobre el lado lingual y otra sobre el mesial o distal.

3) Con tres facetas: una sobre la cara lingual, otra sobre la mesial y otra sobre la distal; una sobre la cara lingual, otra sobre la labial y otra sobre la mesial o distal; una sobre la cara labial, otra sobre la mesial y la otra sobre la distal.

4) Con cuatro facetas: una menor sobre la cara labial, otra mayor sobre la lingual y dos laterales, sobre la mesial y distal.

Aquellos dientes que no poseen superficies de desgaste son aquí interpretados como dientes no funcionales: son dientes de reemplazo que, al no haber erupcionado, al menos totalmente, aún no comenzaron a friccionarse con otros dientes.

Los dientes con una única faceta de desgaste, frecuentemente presentan esta superficie de contacto centrada sobre la cara lingual (e.g. MPCA-Pv- 88, 89, 108, 752, 757, MCSPv- 93, 95, 102). Su morfología es elíptica, lo que genera que el ápice del diente termine en una punta aguda (figura 5.1). El ángulo generado 
entre el plano de la faceta de desgaste y el eje axial del diente es muy agudo, generalmente menor a $20^{\circ}$ e incluso la faceta llega a estar paralela al eje axial del diente $\left(0^{\circ}\right)$.

Numerosos dientes poseen una única faceta ubicada centrolateralmente (e.g. MPCA-Pv- 150, 164, 742, 755, MCSPv-101, MML- 221), ubicada siempre algo lingual y lateralmente ya sea mesial o distal (figura 5.2). El desarrollo de este tipo de facetas (centrolateral o lateral) es muy variable en tamaño y morfología, pudiendo abarcar más de la mitad (apicoradicalmente) de la corona del diente (figura 5.2). En cuanto a su morfología, tiende a ser aproximadamente elíptica. En todos estos ejemplos de faceta úni$\mathrm{ca}$, la superficie de desgaste no presenta una diferencia relevante entre el plano de la dentina y el borde circundante del esmalte, observándose la faceta de desgaste completa en un sólo plano, sin relieves.

En los dientes que poseen una única faceta, pero en la cara labial del diente (e.g. MPCA-Pv- 84, 109, 120, $185,224,724)$, el ángulo siempre es mayor que en los diente con una única faceta del lado lingual, y generalmente nunca es menor a $20^{\circ}$ ni mayor a $45^{\circ}$ (figura 5.3).

Otro tipo de patrón bastante claro y constante en los dientes es aquel con dos facetas de desgaste. Una de ellas en la cara labial (la más desarrollada), la otra sobre la cara lingual (e.g. MPCA-Pv- 55, 120, 184, 732, MCSPv- 91, entre otros) (figura 5.4). La condición inversa, la faceta más desarrollada sobre la cara lingual y la menor sobre la cara labial del diente, se observa en los ejemplares MPCA-Pv- 76, 105, 147, 720, 750, MCSPv- 90, 98, entre otros (figura 5.5). La morfología de la faceta de estos dientes es notoriamente diferente a la descripta previamente para los dientes con una única faceta. El ápice de estos dientes es generalmente recto y perpendicular al eje axial. De esta manera, ambas superficies de desgaste adquieren una forma de "V", aunque la faceta labial en numerosos ejemplos posee el vértice de la " $V$ " más redondeado, re- cordando más a una "U" (figura 5.5, b). La inclinación de las facetas difiere en la lingual y la labial; la primera posee un ángulo con respecto al eje axial del diente entre $0^{\circ}$ (paralela) y $33^{\circ}$, mientras que la faceta labial o externa (sea la más desarrollada o no) siempre presenta un ángulo mayor, entre $15^{\circ}$ y $45^{\circ}$. En este tipo de dientes es posible observar una diferencia morfológica entre ambas facetas, además de su diferente grado de desarrollo e inclinación. La faceta lingual, del mismo modo que los dientes con una única faceta de desgaste, se desarrolla en un plano, sin ningún relieve significativo entre la dentina y el esmalte. Mientras que el plano en el cual se desarrolla la faceta labial (no siempre) presenta un importante desnivel entre la dentina y el esmalte, formando este último un contorno prominente que limita la faceta (figura 6.1). Este relieve es, según Sereno et al., (2007) para los dientes de Nigersaurus, el producto del contacto entre diente y el material vegetal. El último tipo de dientes, con dos facetas, presenta la primera de ellas ubicada centralmente sobre el lado lingual, una superficie de desgaste ubicada como la descrita para los dientes con una faceta única sobre su lado lingual, y una segunda faceta ubicada lateral y algo ventral (mesial o distal) a la anterior (e.g. MPCAPv- 96, 106, 128, 721, 723, MCSPv- 167, MML- 223). La faceta lateral puede estar, como se observa en numerosos ejemplares, más desarrollada que la lingual (figura 5.6), así como también desconectada de ésta.

En los dientes con un patrón de tres facetas, puede observarse casi siempre una de ellas de posición lingual. Las dos restantes, en algunos casos, se ubican mesial y distalmente, (e.g. MPCA-Pv- 102, 747, 754, MCSPv- 97) (figura 5.7), mientras que otros, además de la faceta lingual, presentan una pequeña faceta labial y otra lateral, mesial o distal (e.g. MPCA-Pv- 48, 204, 715, 753) (figura 5.8). La tercera combinación de tres facetas, está presente en un sólo ejemplar (MPCA-Pv- 138), y lleva una faceta labial y dos laterales, mesial y distal (fi-

Figura 5. Fotografías de dientes de Titanosauria indet. exponiendo las facetas de desgaste, junto a éstas, sus interpretaciones gráficas. 1, (MCSPv- 93), diente con una única faceta sobre el lado lingual. 2, (MPCA-Pv-742), diente con una única faceta sobre el lado lateral, mesial o distal. 3, (MPCA-Pv-120), diente con una única faceta sobre el lado labial. 4, (MPCA-Pv-55), diente con dos facetas, la mayor sobre el lado labial y la menor lingual. 5, (MPCA-Pv-76), diente con dos facetas, la mayor sobre el lado lingual y la menor labial. 6, (MPCAPv-96), diente con dos facetas, una sobre el lado lingual y otra mesial o distal. 7, (MPCA-Pv-102), diente con tres facetas, una sobre la cara lingual, otra mesial y otra distal. 8, (MPCA-PV-48), diente con tres facetas, una sobre la cara lingual, otra labial y otra mesial o distal. 9, (MPCA-Pv-138), diente con tres facetas, una sobre la cara labial, otra mesial y otra distal. 10, (MPCA-Pv-72), diente con cuatro facetas, una menor sobre el lado labial, otra mayor sobre el lado lingual y dos laterales, mesial y distal. Los dientes 1, 2, 5-8 y 10 probablemente pertenezcan a la mandíbula superior. Los dientes 3, 4 y 9 probablemente pertenezcan a la mandíbula inferior. a, vista lingual; $\mathbf{b}$, vista labial; c, vista mesial o distal. Escala $1=\mathrm{cm} /$ Titanosauria indet. teeth showing the wear facet (photograph and interpretative drawing). 1, (MCSPv93), tooth with only one lingual facet. 2, (MPCA-Pv-742), tooth with only one lateral facet, mesial or distal. 3, (MPCA-Pv-120), tooth with only one labial facet. 4, (MPCA-Pv-55), tooth with two facets, the bigger labial and the smaller lingual. 5, (MPCA-Pv-76), tooth with two facets, the bigger lingual and the smaller labial. 6, (MPCA-Pv-96), tooth with two facets, one on the lingual side and another mesial or distal side. 7, (MPCA-Pv-102), tooth with three facets, one on the lingual side, the others on the mesial and distal sides. 8, (MPCA-Pv-48), tooth with three facets, one on the lingual side, the others on the labial and mesial or distal sides. 9, (MPCA-Pv-138), tooth with three facets, one on the labial side, the others on the mesial and distal sides. 10, (MPCA-Pv-72), tooth with four facets, the smaller on the labial side, the bigger on the lingual side, and two lateral, on the mesial and distal sides. Teeth 1, 2, 5-8 and 10 probably belong to the upper jaw. Teeth 3, 4 and 9 probably belong to the low jaw. a, lingual view; $\boldsymbol{b}$, labial view, $c$, mesial or distal view. Scale bar $1=\mathrm{cm}$. 


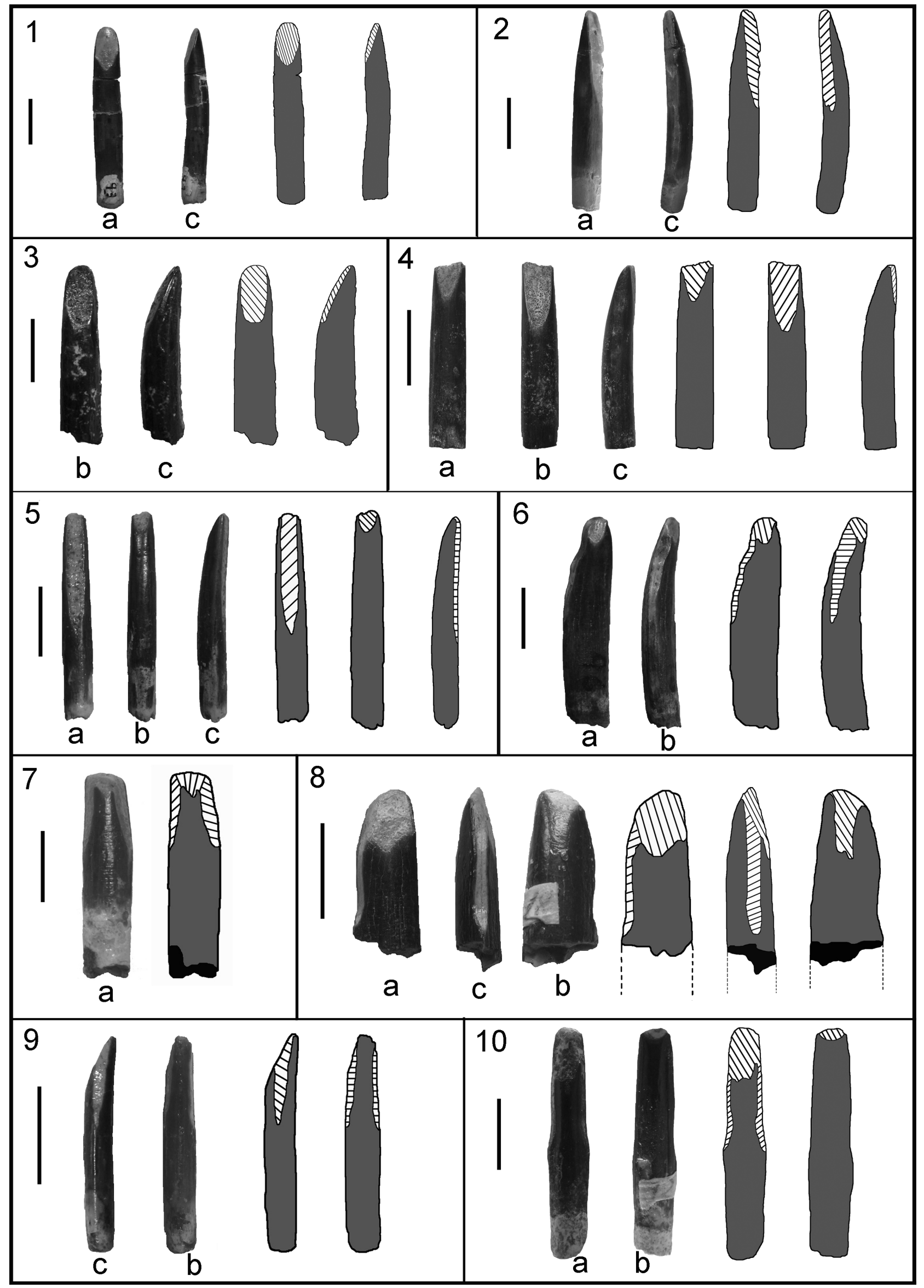

AMEGHINIANA 47 (1), 2010 
gura 5.9). En algunos especimenes que poseen facetas laterales, éstas se presentan como una extensión o prolongación de la faceta principal (lingual) que se dirige hacia la raíz del diente. En otros ejemplares, alguna de las facetas laterales o ambas, se encuentra de manera independiente a la faceta lingual.

El último patrón está representado por dientes con cuatro facetas de desgaste (e.g. MPCA-Pv- 52, 72, 151, 717, 748) (figura 5.10). Este patrón es el menos frecuente en los materiales estudiados, pero es sin duda el más complejo de todos. Aquí la faceta menos desarrollada y la de mayor ángulo, siempre con respecto al eje axial del diente, está ubicada del lado labial del diente. Sobre el lado lingual se encuentra una amplia faceta con un bajo ángulo, que en numerosos ejemplares, como en algunos especimenes de tres facetas, se continúa lateralmente hacia la raíz del diente, formando dos facetas elongadas. Estas últimas dos superficies de desgaste son siempre paralelas al eje axial del diente, delgadas y con un leve ensanchamiento hacia el extremo radical (basal). Otros ejemplares de esta misma categoría, presentan las dos facetas laterales sin conexión con las facetas labial y/o lingual (figura 5.10).

\section{Micro-desgaste en las facetas}

La faceta es el resultado del micro-desgaste continuado a lo largo del tiempo. Por lo tanto, y de acuerdo con la hipótesis desarrollada más adelante sobre el origen de estas estructuras, las facetas poco desarrolladas habrían sido aquellas que tuvieron menor tiempo de exposición al agente de fricción. A partir de la morfología e inclinación de la faceta de desgaste, pero sobre todo del análisis del patrón del microdesgaste, es posible inferir el tipo de movimiento que tuvo la mandíbula, así como sugerir el tipo de alimentación que habrían tenido estos animales (Fiorillo, 1998; Upchurch y Barrett, 2000; Schubert y Ungar, 2005). A través del microscopio óptico y el microscopio electrónico de barrido, las superficies de desgaste sobre la dentina revelan numerosas y finas estrías o scratches, orientadas paralelas y subparalelas al eje mayor de la faceta (figura 6.2), las cuales están directamente relacionadas al tipo de movimiento de la mandíbula. En función de la orientación de las estrías, del bajo ángulo que poseen las facetas de desgaste (nunca mayor a $45^{\circ}$ en la faceta labial) y teniendo en cuenta que este desgaste es el resultado de la fricción entre los dientes superiores e inferiores, los titanosaurios habría ejercido un movimiento unidireccional tipo ortal (hacia arriba y abajo) como lo sugirieron Calvo (1994), Chatterjee y Zheng (2002) y Sereno et al. (2007).

Un segundo rasgo observado con altos aumentos, es la presencia de hoyuelos o pits, tanto en las facetas de desgaste (dentina y esmalte) como sobre el resto de la superficie del diente (sobre el esmalte) (figura 6.1). En los especimenes que presentan los pits sobre la faceta de desgaste (e.g. MCSPv-91, MPCA-Pv-20, $97,184,185,201,717,720)$, estos hoyuelos se encuentran densamente agrupados y superficialmente pulidos.

En unos pocos dientes (e.g. MPCA-Pv- 18, 151, 201, 720,737 ) (figura 6.1) es posible observar la faceta de desgaste limitada por un pequeño reborde de esmalte; según Sereno et al. (2007), este pequeño reborde es el producto de la abrasión con la materia vegetal. Sin embargo, el patrón más común en los dientes de titanosaurios estudiados es la faceta en un sólo plano, estando la dentina y el esmalte desgastados por igual. Es probable que en estos saurisquios el esmalte y la dentina hayan tenido una dureza similar y quizás su composición o micro-estructura difiera de la de otros vertebrados, en los cuales el esmalte es considerablemente más resistente a la fricción que la dentina, generando un desgaste desigual. El aspecto superficial del esmalte en la mayoría de los especimenes examinados es, dependiendo del ejemplar, leve o intensamente rugoso en la base de la corona. Esta rugosidad disminuye gradualmente hacia el ápice del diente en todos los ejemplares, hasta presentar un aspecto liso, brillante y muy pulido (excepto por algunas estrías y/o pits). En los dientes no funcionales, el aspecto del esmalte es notablemente rugoso, alcanzando con esa textura (rugosa) el ápice del diente.

\section{Hipótesis sobre el origen de las facetas de desgaste}

A partir del gran número de dientes observados, particularmente de la morfología de la facetas de desgaste, se propone seguidamente una explicación acerca del posible mecanismo por el cual se habrían generado esas superficies. En titanosaurios, el diente funcional es acompañado en su alvéolo por tres dientes de reemplazo (Coria y Chiappe, 2001; obs. pers.), al menos en los premaxilares y dentarios. El número de dientes de reemplazo por alvéolo es aún mayor en los diplodocoideos Diplodocus y Nigersaurus: cinco y siete respectivamente (Hatcher, 1901; Sereno et al., 1999). La explicación que se desarrolla a continuación es, fundamentalmente, para la presencia simultánea de facetas de desgastes en la cara lingual y labial.

Como se muestra en la figura 7, los dientes superiores (premaxilares y maxilares), contactan lingualmente sobre la cara labial de los dientes inferiores (dentarios), una condición usual en saurópodos (Nowinski, 1971; Calvo, 1994; Sereno y Wilson, 2005). Como se mencionó anteriormente, al menos algunos saurópodos (entre ellos los titanosaurios) habrían tenido un 


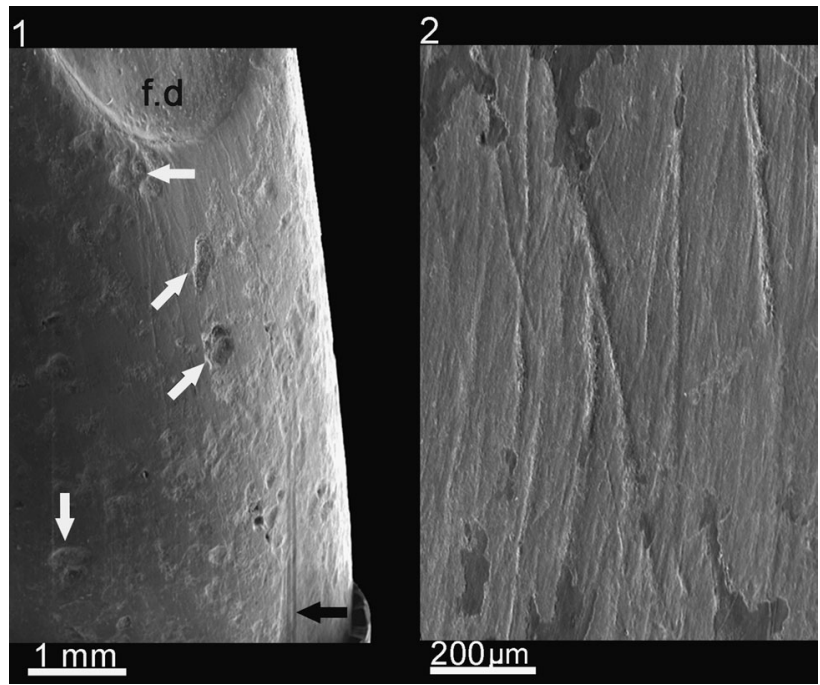

Figura 6. Diente de Titanosauria indet. (MPCA-Pv-18). 1, detalle del límite de la faceta de desgaste y del micro-desgaste sobre la superficie del diente. 2 , detalle de la superficie de la faceta de desgaste mostrando las finas estrías; las estrías se orientan paralelas al eje longitudinal de la faceta. f.d, faceta de desgaste; las flechas blancas señalan hoyuelos o pits; la flecha negra señala estrías o scratches / Titanosauria indet. tooth (MPCA-Pv-18). 1, detail of the limit of the wear facet and the micro-wear of the tooth surface. 2, detail of the wear facet surface showing fine scratches; the scratches are parallel to the longitudinal axis of the wear facet. f.d, wear facet; white arrows are pointing pits; black arrow is pointing scratches.

movimiento mandibular de tipo ortal (Calvo, 1994; Chatterjee y Zheng, 2002). A partir de un movimiento de este tipo, los dientes superiores (identificados con números en la figura 7) contactarían a través de su superficie lingual con la superficie labial del diente inferior (identificados con letras en la misma figura), al menos por el período de tiempo en que estos dos sean funcionales. De esta manera, el primer diente superior $\left(\mathrm{N}^{\circ}\right.$ 1 de la figura 7.1), presenta una faceta de desgaste bien desarrollada en su cara lingual (ejemplo figura 5.1), mientras que el primer diente inferior (diente a de la figura 7.1), expone una faceta de desgaste ampliamente desarrollada sobre la superficie labial (ejemplo figura 5.3). El diente $\mathrm{N}^{\circ} 2$ al reemplazar al diente funcional $\mathrm{N}^{\circ}$ 1 (figura 7.1, 2), contactaría (al menos durante el período de tiempo que tarda en erupcionar totalmente y ubicarse en la posición que dejó el diente reemplazado $N^{\circ} 1$ ) a través de su superficie labial, con la cara lingual del diente inferior (a). De este modo, se genera sobre el diente inferior (a) una nueva faceta de desgaste de pequeño tamaño sobre su cara lingual. Ésta, junto a la faceta mayor ubicada sobre su cara labial, forman un diente similar al presente en la figura 5.4. Al ser reemplazado el diente inferior (a), su reemplazo, el diente (b) (figura 7.2, 3), contactaría su cara labial con la superficie lingual del diente superior $\mathrm{N}^{\circ} 2$, generándose en este último dos facetas, como en el diente presente en la figura 5.5. De este modo, en los sucesivos reem-
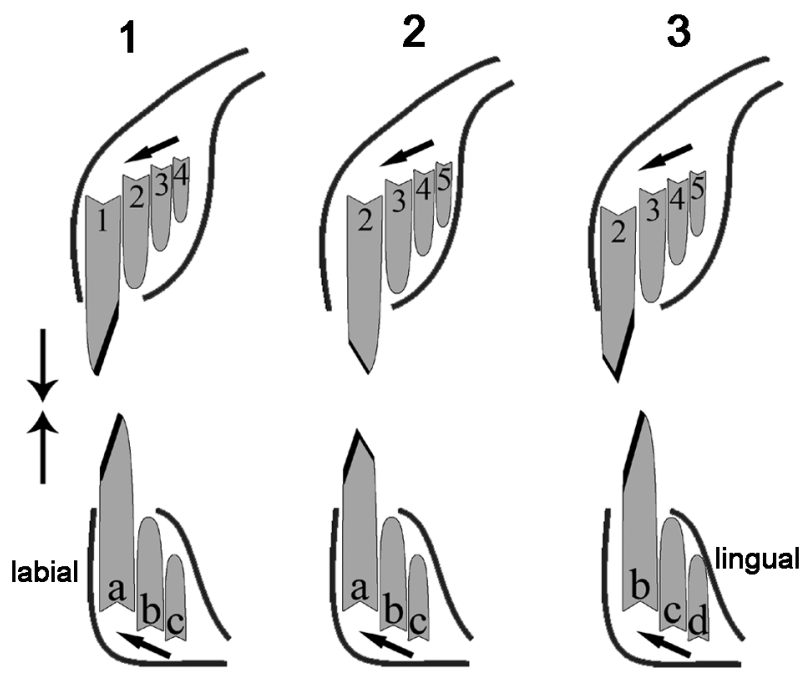

Figura 7. Representación gráfica de la hipótesis de cómo se habrían generado las facetas de desgaste sobre los dientes de titanosaurios. Las flechas verticales indican el tipo de movimiento de la mandíbula; las flechas más pequeñas indican el desplazamiento de los dientes. a-d, dientes del dentario; 1-5, dientes del premaxilar o maxilar / graphic representation of the hypothesis about wear facet origin in titanosaurian teeth. The vertical arrows pointing mandibular movement; the smaller arrow pointing teeth displacement. $\boldsymbol{a}-\boldsymbol{b}$, dentary teeth; 1-5 premaxillary or maxillary teeth.

plazos se habrían generado dientes con facetas de desgaste en ambas caras (labial y lingual) tan comunes en los dientes de titanosaurios estudiados.

\section{Discusión y conclusión}

A pesar de que el dentario estudiado (MCSPv061) es fragmentario, la preservación de siete de los 11 o 13 alvéolos totales permite comprobar que los dientes poseían un patrón de reemplazo de tipo alternante. Es posible confirmar que, adicionalmente al diente funcional, este especimen llevaba dos dientes de reemplazo por alvéolo. Como se observa en los sucesivos cortes delgados efectuados sobre el dentario, los gérmenes precursores de los dientes se originan profundamente en los alvéolos, siempre desde el lado lingual al diente que lo precede (diente en un estado de desarrollo más avanzado). A medida que se desarrollan, los dientes inmaduros se desplazan desde lo profundo del alvéolo hacia una posición más labial y superficial, ocupando finalmente el lugar del diente funcional. Si bien no es posible conocer la tasa de recambio dentario en estos titanosaurios, la escasa diferencia de tamaño entre el diente funcional y el primer diente de reemplazo en alguno de los alvéolos preservados sugiere un rápido recambio. En base a la serie de alvéolos preservados, el tipo de reemplazo inferido es de tipo alternante (Edmund, 1960, Romer, 1966), similar al de numerosos reptiles (Ed- 
mund, 1960). Este tipo de reemplazo no implica que el espécimen haya estado continuamente con la mitad de sus dientes funcionando, sino sólo que la sustitución de los dientes tiene lugar en "ondas" que se desplazan a lo largo de la rama mandibular (véase White, 1958; Romer, 1966; Nowinski, 1971).

La morfología de los dientes del dentario es similar a la de numerosos dientes aislados también estudiados aquí. Por otro lado, las secciones histológicas descriptas permiten obtener información concerniente a los principales tejidos involucrados en la inserción dentaria del individuo (hueso alveolar, cemento y ligamento periodontal). En primer lugar, la conformación micro-estructural del hueso alveolar es semejante a la descripta para otros vertebrados, donde la matriz se compone principalmente por hueso entretejido (woven fibered bone) (Caldwell et al., 2003). La presencia de al menos dos generaciones distintas de hueso alveolar sugiere una activa remodelación del tejido ligada al constante recambio dental del individuo. A diferencia de lo que ocurre en Camarasaurus Cope, 1877 (el único saurópodo donde se han estudiado los tejidos de inserción dentaria), donde el hueso alveolar tiende a compactarse hacia la porción superior del alvéolo (Reid, 1996), el hueso alveolar examinado en este dentario mantiene su aspecto finamente esponjoso en todas las secciones. Otra diferencia observada con Camarasaurus estriba en la ausencia por parte de este último taxón de espacios de reabsorción de forma ovalada que albergan los dientes de reemplazo más profundos. Con respecto al cemento, los resultados obtenidos en este trabajo permiten reconocer, por primera vez en un dinosaurio no aviano, este tejido. En términos generales, la micro-estructura del cemento celular se asemeja a la descripta para mamíferos y cocodrilos. El cemento celular se caracteriza por ser una capa delgada y avascular de tejido que recubre al diente en su raíz, sin alcanzar la porción basal del esmalte. A diferencia de lo descrito en mamíferos y otros reptiles (Berkovitz y Sloan, 1979; Caldwell et al., 2003; Riviere y Wheeler, 2005), no se identificaron fibras de Sharpey en el cemento celular. Asimismo, el cemento carece completamente de líneas de incremento. En cuanto a la aparente ausencia de cemento acelular en las muestras, es posible que la misma no se deba a una ausencia real del tejido, sino a que el mismo no pudo ser identificado por la alteración diagenética sufrida por el especimen. En cuanto al ligamento periodontal, las trazas de esta estructura aparecen como fibras de Sharpey embebidas en el hueso alveolar que ocupa la porción más superior del alvéolo. Su orientación, casi paralela al margen interno del alvéolo, difiere de la observada en cocodrilos actuales, donde las fibras se proyectan de forma oblicua (Berkovitz y Sloan, 1979). Esta orientación posiblemente esté ligada al importante diámetro de los dientes de los tita-

AMEGHINIANA 47 (1), 2010 nosaurios. Si bien el material estudiado consta de un sólo individuo, el cual además se encuentra alterado diagenéticamente, el análisis histológico ha brindado valiosa información concerniente a los tejidos de inserción dentaria en un titanosaurio. Sin embargo, es necesario continuar con análisis histológicos de este tipo, puesto que el incremento de muestras obtenidas a partir de distintos grupos de saurópodos permitirá sin duda efectuar un análisis comparativo amplio de las estructuras de inserción dentaria y comprender la evolución de las mismas. Sólo de esta forma podrá establecerse cuán conservativo es el patrón observado en titanosaurios, y cómo éste puede relacionarse con la dinámica de recambio dental.

Todos los dientes estudiados, a pesar de presentar una importante diversidad morfológica, poseen la típica "forma de cincel o lápiz" propia de los titanosaurios (Calvo, 1994). La diversidad en tamaño y morfología sugiere que los dientes analizados pertenecen a diferentes clases de edades y a diferentes especies. Sin embargo, debe recordarse que no es posible asignar taxonómicamente elementos aislados.

Las facetas de desgaste de un gran número de los especimenes analizados se ajustan con la clasificación aquí propuesta, sin embargo, éstas no son del todo discretas. Numerosos dientes presentan una combinación de diferentes tipos de desgaste algo más complejas, excediendo las categorías mencionadas. Kellner (1996) y Costa Franco-Rosas (2004) interpretan algunas facetas de desgaste (principalmente aquellas complejas, que no se ajustan a la clasificación aquí propuesta) del mismo modo que aquí se han interpretado las facetas laterales, como propias de dientes que por algún motivo erupcionaron fuera de su trayectoria original (desviando su dirección, ubicación, etc.), desde sus respectivos alvéolos. Aquellos dientes desviados de su estricta trayectoria eruptiva contactarían, no sólo con el diente que le corresponde en la mandíbula opuesta, sino también con dientes de alvéolos adyacentes a éste.

El micro-desgaste ha sido utilizado en numerosos taxones por diferentes autores para inferir sus dietas (Fiorillo, 1991, 1997, 1998, 2008; Calvo, 1994; Wilson, 2005, Sereno et al., 2007). En el presente trabajo, a pesar de observar claramente el micro-desgaste en numerosos especimenes, no se ha hecho tal conjetura. Las facetas, como ya se mencionó, se habrían originado a partir del contacto diente-materia vegetaldiente o diente-diente, a partir de una constante fricción. A pesar de esto, consideramos que los caracteres del micro-desgaste no se corresponden de una manera tan fiel al tipo de material consumido. En esta correspondencia, como notaron Fiorillo (1998) y Upchurch y Barrett (2000), habría cumplido un rol muy importante la cantidad y el tipo del material pétreo (sedimento, granos de arena, etc.) que se hallaba 
junto al alimento consumido, el cual seguramente generaba gran parte de ese micro-desgaste. Por otro lado, los escasos trabajos paleobotánicos realizados en las formaciones portadoras y sitios de hallazgo de los dientes, indudablemente limitan tales inferencias. De todas formas, es posible que el pulido superficial del esmalte sobre el área apical de los dientes funcionales, haya sido el resultado del rozamiento constante del diente con el material vegetal blando, si es que efectivamente ingirieron material de este tipo.

La hipótesis propuesta para explicar la formación de las facetas permite, a partir de piezas aisladas, diferenciar dientes dentarios, premaxilares o maxilares. Los dientes superiores (premaxilares y maxilares) habrían llevado la faceta de desgaste más desarrollada sobre su cara lingual y el desgaste menor sobre la cara labial, mientras que los dientes inferiores (sobre el dentario), presentan la faceta más desarrollada en la cara labial y la menor sobre la cara lingual. Las facetas laterales (en aquellos dientes que las poseen) se generarían por procesos casuales, es decir que, por algún motivo, los dientes habrían emergido algo inclinados, desviados de su eje vertical, entrando en contacto no sólo con la cara labial o lingual del diente que le corresponde (superior o inferior), sino también con la cara mesial o distal de un diente contiguo. Así, en este diente, se generaría una faceta de desgaste irregular, muy común entre los especimenes estudiados.

\section{Agradecimientos}

Agradecemos a A. Ruffini de la Universidad Nacional del Comahue (CRUB) por habernos facilitado del equipamiento para el fotografiado de numerosas muestras. A los árbitros J.L. Carballido, J.I. Ruiz-Omeñaca y al Comité Editor por los comentarios referidos al manuscrito. A. Garrido del Museo Olsacher de Zapala, Neuquén, por permitir gentilmente el acceso al equipamiento del laboratorio. Especialmente a C. Muñoz del Museo Carlos Ameghino de Cipolletti, a D. Cabaza del Museo Municipal de Lamarque y a O. Hevia del Museo Cinco Saltos por habernos permitido estudiar el material depositado en mencionados museos. R. Coria permitió la confección de réplicas en instalaciones del Museo "Carmen Funes" de Plaza Huincul. También agradecemos al equipo del policlínico Neuquén (M. Quintili y J.J. Perazzola) por facilitarnos el tomógrafo. El trabajo ha sido financiado por el CONICET (PIP 6455) y Agencia de Promoción Científica y Técnica (PICT 357).

\section{Bibliografía}

Apesteguia, S. 2004. Bonitasaura salgadoi gen. et sp. nov.: a beaked sauropod from the Late Cretaceous of Patagonia. Journal Naturwissenschaften 91: 493-497.

Ballent, S.C. 1980. Ostrácodos de ambiente salobre de la Formación Allen (Cretácico Superior) en la provincia de Río Negro (República Argentina). Ameghiniana 17: 67-82.

Barrett, P.M., Hasegawa, Y., Manabe, M., Isaji, S. y Matsuoka, H. 2002. Sauropod dinosaurs from the Lower Cretaceous of Eastern Asia: Taxonomic and Biogeographical implications. Palaeontology 45: 1197-1217.
Berkovitz, B.K.B. y Sloan, P. 1979. Attachment tissues of the teeth in Caiman sclerops (Crocodilia). Journal of Zoology, London 187: 179-194.

Budney, L.A., Cadwell, M.W. y Albino, A. 2006. Tooth socket histology in the Cretaceous snake Dinilysia, with the review of the amniote dental attachment tissues. Journal of Vertebrate Paleontology 26: 138-145.

Caldwell, M.W., Budney, L.A. y Lamoureux, D.O. 2003. Histology of tooth attachment tissues in the Late Cretaceous mosasaurid Platecarpus. Journal of Vertebrate Paleontology 23: 622-630.

Calvo, J.O. 1994. Jaw mechanics in sauropod dinosaurs. Gaia 10: 183-193.

Calvo, J.O. y González-Riga, B.J. 2003. Rinconsaurus caudamirus gen. et sp. nov., a new titanosaurid (Dinosauria, Sauropoda) from the Late Cretaceous of Patagonia, Argentina. Revista Geológica de Chile 30: 333-353.

Calvo, J.O., González-Riga, B.J. y Porfiri, J.D. 2007. A new titanosaur sauropod from the Late Cretaceous of Neuquén, Patagonia, Argentina. Arquivos do Museu Nacional, Rio de Janeiro 65: 485-504.

Chatterjee S. y Zheng, Z. 2002. Cranial anatomy of Shunosaurus, a basal sauropod dinosaur the Jurassic of China. Zoological Journal of the Linnean Society 136: 145-169.

Chatterjee, S. y Zheng, Z. 2005. Neuroanatomy and Dentition of Camarasaurus lentus. En: V. Tidwell y K. Carpenter (eds), Thunder-Lizards The Sauropodomorph Dinosaur, Indiana Unidersity Press. Bloomington and Indianapolis, pp. 199-211.

Coombs, W.P. 1975. Sauropod habits and habitats. Palaeogoegraphy, Palaeoclimatology, Palaeoecology 17: 1-33.

Cope, E.D. 1877. On a gigantic saurian from the Dakota epoch of Colorado. Paleontological Bulletin 25: 5-10.

Coria, R.A. y Chiappe, L. 2001. Tooth remplacement in a sauropod premaxilla from the Upper Cretaceous of Patagonia Argentina. Ameghiniana 38: 463-466.

Costa Franco-Rosa, A. 2004. [Metodologias para identificação taxonomica com base na estructura dentária, microestructura do esmalte e microanálises química de dentes de sauropodomorpha, theropoda e crocodylomorpha. Tesis Doctoral, Rio de Janeiro, 182 pp. Inédito.].

Curry Rogers, K. y Forster, C.A. 2001. The last of the dinosaur titans: a new sauropod from Madagascar. Nature 412: 530-543.

Curry Rogers, K. y Forster, C.A. 2004. The skull of Rapetosaurus krausei (Sauropoda: Titanosauria) from the Late Cretaceous of Madagascar. Journal of Vertebrate Paleontology 24: 121-144.

Digregorio, J.H. y Uliana, M.A. 1979. Cuenca Neuquina. En J.C.M. Turner (ed.), $2^{a}$ Simposio de Geología Regional Argentina (Córdoba), Academia Nacional de Ciencias (Córdoba) 2: 985-1032.

Dingus, L., Clarke, J., Scott, G.R., Swisher, C.C., Chiappe, L.M. y Coria, R.A. 2000. Stratigraphy and magnetostratigraphic/Faunal constrainst for the age of sauropod embryo-bearing rocks in the Neuquén Group (Late Cretaceous, Neuquén Province, Argentina). American Museum Novitates 3290: 1-11.

Dodson, P. 1990. Sauropod paleoecology. En: D.B. Weishampel, P. Dodson, y H. Osmólska (eds.), The Dinosauria, University of California Press, Berkeley, pp. 402-407.

Edmund, A.G. 1960. Tooth replacement phenomena in the lower vertebrates. Contributions Life Science Division. Royal Ontario Museum 52: 1-190.

Erickson, G.M. 1997. Tooth replacement patterns. En: P.J. Currie y K.Padian (eds.), Encyclopedia of Dinosaurs, Academic Press, San Diego, California/London, UK. pp. 739-740.

Filippi, L.S. y Garrido, A.C. 2008. Pitekunsaurus macayai gen. et sp. nov., nuevo titanosaurio (Saurischia, Sauropoda) del Cretácico Superior de la Cuenca Neuquina, Argentina. Ameghiniana 45: 575-590.

Fiorillo, A.R. 1991. Dental microwear on the teeth of Camarasaurus and Diplodocus: Implications for sauropod paleoecology. En: Z. Kielan-Jaworowska, N. Heintz y H.A. Nakrem (eds.), Terrestrial Ecosystems and Biota, Fifth Symposium on Mesozoic University Oslo, Oslo. pp. 364: 23-24. 
Fiorillo, A.R. 1997. Tooth Wear. En: P.J. Currie y K. Padian (eds.), Encyclopedia of Dinosaurs, Academic Press, San Diego, California/London, UK. pp. 743-745.

Fiorillo, A.R. 1998. Dental microwear patterns of the sauropod dinosaurs Camarasaurus and Diplodocus: Evidence for resource partitioning in the Late Jurassic of North America. Historical Biology 13: 1-16.

Fiorillo, A.R. 2008. Lack of variability in feeding patterns of the sauropod dinosaur Diplodocus and Camarasaurus (Late Cretaceous, Western USA) with respect to climate as indicated by tooth wear features. En: J.T. Sankey y S. Baszio (eds.), Vertebrate Microfossil Assemblages, their role in Paleoecology and Paleobiogeography, Indiana University Press, pp. 104-116.

Gaengler, P. 2000. Evolution of tooth attachment in lower vertebrates to tetrapods. En: M.F. Teaford, M.M. Smit y W.J. Ferguson (eds.), Development, Funtion and Evolution of Teeth, Cambridge University Press, Cambridge, pp. 173-185.

Gilmore, C.W. 1922. A new sauropod dinosaur from the Ojo Alamo Formation of New Mexico. Smithsonian Miscellaneous Collections 72: 1-9.

Gomani, E.M. 2005. Sauropod Dinosaur from the Early Cretaceous of Malawi, Africa. Palaeontologia Electronica 8: 1-37. http:// palaeo-electronica.org/paleo/2005_1/gomani27/issue1 05.htm

Haas, G. 1963. A proposed reconstruction of the jaw muscle of Diplodocus. Annals of Carnegie Museum 36: 139-157.

Hay, O.P. 1908. On the habits and the pose of the sauropodous dinosaurs, especially of Diplodocus. The American Naturalist 42: 672-681.

Hatcher, J.B. 1901. Diplodocus (Marsh): its osteology, taxonomy, and probable habits, with a restoration of the skeleton. $\mathrm{Me}$ moirs of the Carnegie Museum 1: 1-64.

Holland, W.J. 1924. The skull of Diplodocus. Memoirs of the Carnegie Museum 9: 379-403.

Huene, F. 1929. Los saurisquios y ornitisquios del Cretáceo Argentino. Anales del Museo de La Plata (series 3) 3: 1-196.

Hummel, J., Gee, C.T., Sudekum, K.H., Sander, P.M., Nogge, G. y Clauss, M. 2008. In vitro digestibility of fern and gymnosperm foliage: implications for sauropod feeding ecology and diet selection. Preoceeding of The Royal Society B 275: 1015-1021.

Kellner, A.W. 1996. Remarks on Brazilian dinosaurs. En: F.E. Novas, y R.E. Molnar (eds.), Proceeding of the Gondwanan Dinosaur Symposium. Memoirs of the Queensland Museum 29: 489-532.

Kues, B.S., Lehman, T. y Rigby, J.K. Jr. 1980. The teeth of Alamosaurus sanjuanensis a Late Cretaceous sauropod. Journal of Paleontology 54: 864-869.

Madsen, J.R., McIntosh, J.S. y Berman, S.D. 1995. Skull and atlasaxis complex of the Upper Jurassic Sauropod Camarasaurus Cope (Reptilia: Saurischia). Bulletin of Carnegie Museum of Natural History 31: 1-115.

Marsh, O.C. 1878. Principal characters of American Jurassic dinosaurus. Part 1. American Journal of Science 3: 411-416.

Nowinski, A. 1971. Nemegtosaurus mongoliensis n. gen., n. sp. (Sauropoda) from the Uppermost Cretaceous of Mongolia. Palaeontologia Polonica 25: 57-81.

Osborn, H.F. 1899. A skeleton of Diplodocus. Memoirs of the American Museum of Natural History 1: 191-214.

Osborn, J.W. 1977. The interpretation of patterns in dentitions. Biological Journal of the Linnean Society 9: 217-229.

Powell, J.E. 1979. Sobre una asociación de dinosaurios y otras evidencias de vertebrados del Cretácico Superior de la región de La Candelaria, Prov. de Salta, Argentina. Ameghiniana 16: 191204.
Reid, R.E.H. 1996. Bone histology of the Cleveland-Lloyd dinosaurs and of dinosaurs in general, Part I: introduction to bone tissues. Brigham Young University, Geological Studies 41: 2571.

Riviere, H.R. y Wheeler, H.T. 2005. Cementum on Smilodon sabers. The Anatomical Record Part A 285: 634-642.

Romer, A.S. 1966. Anatomía comparada. Editorial Interamericana. México, $425 \mathrm{pp}$.

Sander, P.M. y Clauss, M. 2008. Sauropod Gigantism. Science 322: 200-201.

Schubert, B.W. y Ungar, P.S. 2005. Wear faces and enamel spallinig in tyrannosaurid dinosaurs. Acta Palaeontologica Polonica 50: 93-99.

Sereno, P.C. y Wilson J.A. 2005. Structure and evolution of a sauropod tooth battery. En: K.A. Curry Rogers y J.A. Wilson (eds), The Sauropods: Evolution and Paleobiology. University California Press, Berkeley, pp. 157-177.

Sereno, P.C., Beck, A.L., Dutheil, D.B., Larsson, H.C.E., Lyon, G.H., Moussa, B., Sadleir, R.W., Sidor, Ch.A., Varricchio, D.J., Wilson, G.P. y Wilson, J.A. 1999. Cretaceous sauropods from the Sahara and the uneven rate of skeletal evolution among dinosaurs. Science 286: 1342-1347.

Sereno, P.C., Wilson, J.A., Witmer, L.M., Whitlock, J.A, Abdoulaye M., Oumarou I. y Rowe, T.A. 2007. Structural extremes in a Cretaceous dinosaur. PloS ONE 2: e1230.

Stevens, K.A. y Parrish, J.M. 2005. Neck posture, dentition, and feeding strategies in Jurassic sauropod dinosaurs. En: V. Tidwell y K. Carpenter (eds), Thunder-lizards: The Sauropodomorph Dinosaurs. Indiana University Press, Bloomington, pp. 212-232.

Ten Cate, A.R. 1995. The experimental investigation of odontogenesis. International Journal of Developmental Biology 39: 5-11.

Upchurch, P. 1995. The evolutionary history of sauropod dinosaur. Philosophical Transaction of the Royal Society 349: 365-390.

Upchurch, P. 1998. The phylogenetic relationships of sauropod dinosaurs. Zoological Journal of the Linnean Society 124: 43-103.

Upchurch, P. y Barrett, P.M. 2000. The evolution of sauropod feeding mechanisms. En: H.D. Sues (ed.), Evolution of Herbivory in Terrestrial Vertebrates: perspectives from the fósil record. Cambrigde University Press, Cambridge, pp. 79-122.

Upchurch, P., Barrett, P.M. y Dodson P. 2004. Sauropoda. En: D.B. Weishampel, P. Dodson y H. Osmólska (eds.), The Dinosauria. University of California Press, Berkeley Los Angeles London, pp. 259-322.

White, T.E. 1958. The braincase of Camarasaurus lentus (Marsh). Journal of Paleontology 32: 477-493.

Wilson, J.A. 2005. Redescription of the Mongolian Sauropod Nemegtosaurus mongoliensis Nowinski (Dinosauria: Saurischia) and comments on Late Cretaceous Sauropod diversity. Journal of Systematic Palaeontology 3: 283-318.

Wilson, J.A. y Sereno, P.C. 1998. Early Evolution and Higher-level Phylogeny of Sauropod Dinosaurs. Society of Vertebrate Paleontology Memoir 5: 1-68; Suppl. to Journal of Vertebrate Paleontology 18: 1-68.

Recibido: 18 de junio de 2009.

Aceptado: 5 de septiembre de 2009. 